\section{E-065 SOLITAIREX 6X40 REVASCULARIZATION DEVICE FOR M2 SEGMENT THROMBOEMBOLISM: PRELIMINARY SAFETY AND EFFECTIVENESS OUTCOMES}

${ }^{1}$ B Cristiano*, ${ }^{1} \mathrm{~K}$ Cicilioni, ${ }^{2} \mathrm{~J}$ Dye, ${ }^{1} \mathrm{~J}$ Jacobson, ${ }^{1} \mathrm{D}$ Hoss. ${ }^{1}$ Neuroradiology, Loma Linda University Hospital, Loma Linda, CA; ${ }^{2}$ Neurosurgery, Loma Linda University Hospital, Loma Linda, CA

\subsection{6/neurintsurg-2020-SNIS.101}

Background The SolitaireX revascularization device (Medtronic, Irvine, CA) is deliverable through an 021 microcatheter and incorporates a parametric stent design resulting in lower radial force in smaller diameter vessels compared with Solitaire Platinum and Trevo (Stryker Neurovascular, Fremont, CA), in spite of its large $6 \mathrm{~mm}$ diameter. The combination of low radial force and ease of delivery make the device an attractive choice for (M2 segment) thromboembolism.

Purpose To report our preliminary safety and effectiveness outcomes of the SolitaireX $6 \times 40 \mathrm{~mm}(\mathrm{SX})$ for treatment of M2 segment thromboembolism.

Methods Procedure data representing embolectomies performed at a comprehensive stroke center between 9/5/2019 and 2/7/2020 were reviewed for use of the SX. Collected data include location and size of treated arteries, utilization of balloon guide catheters (BGC) or distal aspiration (DAC), and revascularization success (M2 TICI $\geq 2 \mathrm{~B}$ ). Post procedure imaging and clinical data was reviewed for evidence of radiographic complications with the primary safety endpoint being SICH (ECAS definition). 90 day mRS were determined by phone interview by a trained nurse practitioner.

Results 24 cases utilizing the SX were identified during the study period and an M2 segment was treated in 14 instances (7 representing primary $\mathrm{M} 2$ segment occlusions, 2 tandem cervical ICA/M2 occlusions, the remainder salvage following primary M1 segment occlusion). Completion M2 TICI $\geq 2 \mathrm{~B}$ was $12 / 14$ (86\%). 90d mRS scores were available for 5 of the 14 cases representing treated M2 segment thromboemboli with $\mathrm{mRS} \leq 2$ recorded in $2 / 5(40 \%)$. Additional clinical and outcome data is summarized below.

Post procedure SAH was observed in 4/14 (28.6\%) cases and was trace volume in all but one case where there was significant SAH and PH1 hemorrhage. This case represented the only SICH and was observed after two unsuccessful M2 passes of the SX (M2 TICI 0) as salvage following a M1 segment direct aspiration embolectomy. A fifth patient had nonsymptomatic HT1 hemorrhagic conversion. Overall rate of any ICH 5/14 (36\%), rate of SICH 1/14 (7.1\%).

Conclusion The SolitaireX $6 \times 40 \mathrm{~mm}$ revascularization device can be used for M2 segment thromboembolism. The

\begin{tabular}{lll} 
Abstract E-065 Table 1 & Summarized clinical and outcome data \\
\hline Age, Median (IQR) & 84 & $(69.2-86.5)$ \\
\hline Female, N (\%) & 7 & $(50.0)$ \\
Right, N (\%) & 9 & $(64.2)$ \\
NIHSS, Median (IQR) & 16 & $(11.5-18.5)$ \\
Vessel Diameter (mm), Ave. (SD) & 1.75 & $(0.25)$ \\
Completion M2 TICl $\geq 2 B, N(\%)$ & 12 & $(85.7)$ \\
SICH, N (\%) & 1 & $(7.1)$ \\
$90 \mathrm{~d}$ mRS $\leq 2, \mathrm{~N} / \mathrm{N}$ Aval. (\%) & $2 / 5$ & $(40)$ \\
\hline
\end{tabular}

one significant complication in this cohort (SICH due to combined PH1 hemorrhagic conversion and $\mathrm{SAH}$ ) may have been attributable to factors independent of the revascularization device. Treated arteries ranged from $1.5-2 \mathrm{~mm}$ and there was an overall good safety profile and high angiographic success rate.

Disclosures B. Cristiano: None. K. Cicilioni: None. J. Dye: None. J. Jacobson: None. D. Hoss: None.

\section{E-066 FIRST U.S. EXPERIENCE WITH THE R ${ }^{4} Q$ DISTAL ACCESS CATHETER FOR CONTACT ASPIRATION MECHANICAL THROMBECTOMY IN EMERGENT LARGE VESSEL OCCLUSION ACUTE ISCHEMIC STROKE}

${ }^{1} \mathrm{R}$ Torabi*, ${ }^{2} \mathrm{M}$ Mokin, ${ }^{2} \mathrm{Z}$ Ren, ${ }^{3} \mathrm{~A}$ Siddiqui, ${ }^{3} \mathrm{E}$ Levy, ${ }^{3} \mathrm{M}$ Waqas, ${ }^{1} \mathrm{~A}$ Arthur, ${ }^{1} \mathrm{D}$ Hoit, ${ }^{1} \mathrm{C}$ Nickele, 'V Inoa, ${ }^{4} \mathrm{~B}$ Jankowitz. ${ }^{1}$ Neurosurgery, Semmes-Murphey Clinic, Memphis, TN ${ }^{2}$ Neurosurgery, University of South Florida, Tampa, FL; ${ }^{3}$ Neurosurgery, University at Buffalo, Buffalo, NY; ${ }^{4}$ Neurosurgery, Cooper University Health Care, Camden, NJ

\subsection{6/neurintsurg-2020-SNIS.102}

Background Novel devices are being developed to maximize the efficacy of mechanical thrombectomy (MT). The MIVI $\mathrm{R}^{4} \mathrm{Q}$ series of distal access catheters has a unique design with an 0.20 -inch wire $(117 \mathrm{~cm}$ length) that replaces the proximal three quarters of the catheter and is attached to a distal catheter $(25 \mathrm{~cm}$ length). The proximal end is flared with an outside diameter of 0.088 inch so that the outside is sealed with the inside of an $8 \mathrm{~F}$ guide catheter allowing direct aspiration from the guide catheter thus providing greater aspiration force than smaller diameter catheters. This is the first report of patients in the United States using this technology to perform contact aspiration (CA).

Methods We retrospectively reviewed all patients who underwent MT with the $R^{4} \mathrm{Q}$ system at three high volume stroke centers. Baseline demographic and clinical data, as well as technical and clinical outcomes were recorded. Statistical comparison of rates of successful revascularization (SR) mTICI score 2b-3 and first pass effect (FPE) with MIVI technology were compared to the CA arms of ASTER and COMPASS using the Fischer's Exact Test.

Results 32 consecutive patients were identified. Median presenting NIHSS score at admission was 18 . The site of occlusion was the middle cerebral artery M1 segment in 11 (34.4\%), M2 segment in 6 (19\%), M3 segment in 1 (3.1\%), internal carotid artery in 8 (25\%), tandem cervical ICA and intracranial occlusion in $2(6.2 \%), \mathrm{ACA}$ in $2(6.3 \%)$, and basilar artery in $2(6.3 \%)$. The $\mathrm{R}^{4} \mathrm{Q}$ was successfully delivered to the point of occlusion in $28(87 \%)$ patients. SR to $\mathrm{mTICI}$ score $2 \mathrm{~b}-3$ on FPE was achieved in 21/32 (65\%) patients and $16 / 26$ (62\%) patients where the $\mathrm{R}^{4} \mathrm{Q}$ was successfully delivered without a stent retriever. Final mTICI $2 \mathrm{~b}-3$ was achieved in 29/32 (91\%) patients and 26/28 (93\%) patients where the $\mathrm{R}^{4} \mathrm{Q}$ was successfully delivered. Three (9\%) patients had intracranial hemorrhage - all HI1 (ECASS 2), 2 (6\%) patients had vasospasm, and $1(3 \%)$ patient had an embolus to a new territory. Fourteen patients (44\%) had a 90-day modified Rankin scale (mRS) 0-2. SR with MIVI was similar to results from ASTER $(91 \%$ vs. $85 \%, p=0.58)$ and COMPASS $(91 \%$ vs $83 \%, \mathrm{p}=0.41)$. FPE with MIVI was more frequent than in ASTER $(62 \%$ vs. $26 \%, p=0.0009)$ and equivalent to COMPASS $(62 \%$ vs $57 \%, \mathrm{p}=0.83)$ and more frequent in comparison to the combined ASTER and COMPASS cohort (62\% vs. $40 \%, \mathrm{p}=0.04)$. 
Conclusion The $\mathrm{R}^{4} \mathrm{Q}$ family of catheters incorporates novel technology for CA. This series demonstrates a high FPE and similar rates of SR compared with published data using other aspiration catheters. Further prospective studies of this technology are planned to evaluate its clinical efficacy.

Disclosures R. Torabi: None. M. Mokin: 1; C; NIH R21NS109575. 2; C; Medtronic, Canon Medical, Cerenovus. 4; C; Serenity Medical, Synchron, Endostream, VICIS. Z. Ren: None. A. Siddiqui: 1; C; NIH/NINDS, Cerenovus, Medtronic, Microvention, MUSC, Penumbra. 2; C; Amnis Therapeutics, Boston Scientific, Canon Medical Systems USA, Cerebrotech Medical Systems, Cerenovus, Corindus, Endostream Medical, Guidepoint Global Consulting, Imperative Care, Integra, Medtronic, Microvention, Minnetronix Neuro, Northwest University, Penumbra, Q’Apel Medical, Rapid Medical, Rebound Therapeutics, Serenity Medical, Silk Road Medical, StimMed, Stryker, Three Rivers Medical, VasSol, W. L. Gore \& Associates. 4; C; Adona Medical, Amnis Therapeutics, BlinkTBI, Buffalo Technology Partners, Cardinal Consultants, Cerebrotech Medical Systems, Cognition Medical, Endostream Medical, Imperative Care, International Medical Distribution Partners, Neurovascular Diagnostics, Q'Apel Medical, Rebound Therapeutics, Rist Neurovascular, Sense Diagnostics, Serenity Medical, Silk Road Medical, Spinnaker Medical, StimMed Synchron, Three Rivers Medical, VasSol, W.L Gore \& Associates. E. Levy: 2; C; Claret Medical, GLG Consulting, Guidepoint Global, Imperative Care, Medtronic, Rebound Therapeutics, StimMed. 4; C; NeXtGen Biologics, RAPID Medical, Claret Medical, Cognition Medical, Imperative Care, Rebound Therapeutics, StimMed, Three Rivers Medical. 6; C; National PI: Medtronic, Steering committees for SWIFT Prime and SWIFT Direct trials, Honorarium for Training and Lectures: Medtronic, Advisory Board: Styker (AIS clinical advisory board), NeXtGen Biologics, MEDX, Cognition Medical, Endostream Medical, Site PI: Microvention (Confidence Study). M. Waqas: None. A. Arthur: 1; C; Balt, Cerenovus, Medtronic, Microvention, Penumbra, Siemens, Stryker. 2; C; Johnson \& Johnson, Microvention, Medtronic, Penumbra, Scientia, Siemens, Stryker. 4; C; Bendit, Cerebrotech, Endostream, Magneto, Marblehead, Neurogami, Serenity, Synchron, Triad Medical, Vascular Simulations. D. Hoit: 2; C; Medtronic, Microvention. 4; C; Silver Bullet, Cerebrotech, Marblehead Medical. C. Nickele: 1; C; Microvention. 2; C; Leica. V. Inoa: None. B. Jankowitz: 2; C; Stryker, Medtronic.

\section{E-067 REDUCING TIME TO REVASCULARIZATION IN ACUTE ISCHEMIC STROKE}

H Shownkeen, A Doerr*, S Togbi-Wonyo, B Fill, A Mazumdar, D Pandya, A Lindstrom, M Shownkeen. Northwestern Medicine Central Dupage Hospital, Winfield, IL

\subsection{6/neurintsurg-2020-SNIS.103}

Background Endovascular treatment (EVT) of large vessel occlusions in the treatment of disabling strokes is more effective if reperfusion is achieved quickly. Streamlining protocols from patient presentation to groin puncture can lead to improved timelines to treatment and functional outcomes.

Purpose The purpose of this study was to identify the impact of specific hospital based process improvement strategies in the acute ischemic stroke patient population undergoing endovascular therapy with the specific intent to decrease median arrival to groin puncture. Our multidisciplinary events to review pre and intraprocedure work flow as part of a process improvement (PI) project began in November 2018 during fiscal year (FY) 2019 (9/1/2018-9/1/2019) and implementation of recommendations began FY 2020 (9/1/19. 12/31/19).

Methods The study includes a pre- and post-intervention retrospective review of consecutive patients 18 years or older, hospital admission between September 1, 2016 and December 31, 2019, who underwent EVT for treatment of acute ischemic stroke. Patients experiencing acute stroke within an established hospital admission were excluded from analysis. The primary outcome variables were time from arrival to groin puncture and first pass during the acute ischemic stroke admission. The data points were collected from internal stroke review dataset and anonymized prior to analysis. All but two of our cases used general anesthesia.

Results In FYs 2017 (9/1/16-9/1/17) and 2018 (9/1/17-9/1/ 18) before intervention our median door to needle times were 94 minutes in FY 2017 (37 patients) and 113 minutes in FY 2018 (48 patients). Our median door to first pass times were 114 minutes in FY 2017 and 139 minutes in FY 2018. Post intervention our door to groin puncture times were 64 minutes in FY 2019 (64 patients) and 56 minutes in FY 2020 (35 patients). Our median door to first pass times were 86 minutes in FY 2019 and 74 minutes in FY 2020. The drop in door to groin puncture and door to first pass times pre and post intervention were statistically significant $(\mathrm{P}<0.05)$.

Conclusions Having multidisciplinary team events dedicated to PI alone (which provided education and awareness to multiple stakeholders) resulted in a substantial decrease in median door to groin puncture and door to first pass times. Implementation of hospital based PI initiatives to improve work flow including: early endovascular team activation, a streamlined transport process, a streamlined patient preparation process in the lab, and utilization of a feedback tool resulted in continued improvement in door to groin puncture and first pass times.

Disclosures H. Shownkeen: None. A. Doerr: None. S. TogbiWonyo: None. B. Fill: None. A. Mazumdar: None. D. Pandya: None. A. Lindstrom: None. M. Shownkeen: None.

\section{E-068 IMPROVING EFFICIENCY OF ACUTE ISCHEMIC STROKE THERAPIES: REDUCING DOOR-TO-NEEDLE AND DOOR- TO-PUNCTURE TIME}

V Chin*, K Yeboah, A Balushi, A Guthrie, K Christopher, R Edgell. Saint Louis University, Saint Louis, MO

\subsection{6/neurintsurg-2020-SNIS.104}

Introduction/Purpose Early recanalization has been associated with a higher likelihood of favourable clinical outcome in acute ischemic stroke (AIS). It is imperative that stroke systems of care are set up to minimize workflow latencies that delay initiation of reperfusion therapies, i.e. IV tPA and mechanical thrombectomy (MT). Guidelines recommend a maximum door-to-needle (DTN) time of 60 minutes and a door-to-groin puncture time (DGPT) of 90 minutes in 50\% of cases of large vessel occlusion (LVO). We aimed to evaluate various workflow latencies during stroke codes, including door-to-needle and door-to-groin puncture times, prior to and 